$$
\text { Conf-940933--12 }
$$

UCRL-JC-118161

PREPRINT

\title{
Radiation-Driven Targets for Heavy-Ion Fusion
}

D. D.-M. Ho

J. A. Harte

M. Tabak

This paper was prepared for submittal to the

IAEA, 15th International Conference on

Plasma Physics and Controlled Nuclear Fusion Research

Seville, Spain,

September 26 - October 1, 1994.

August 1994

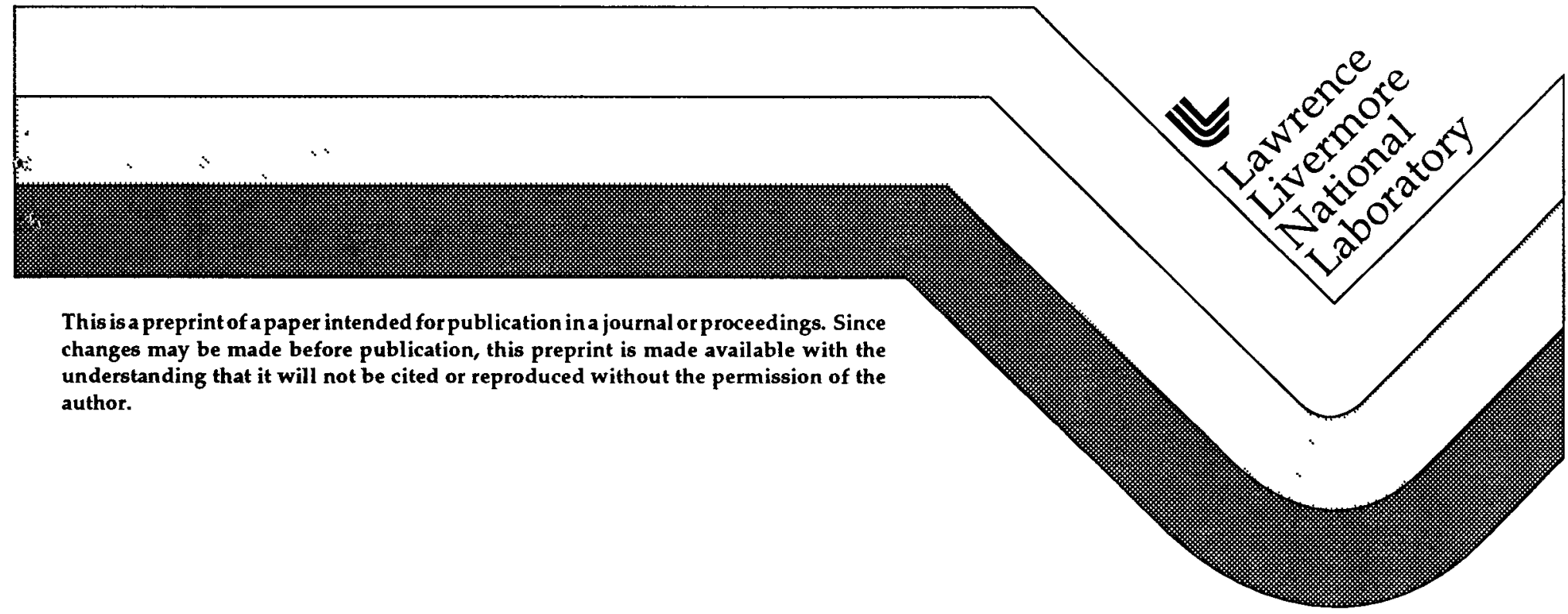




\section{DISCLAIMER}

This document was prepared as an account of work sponsored by an agency of the United States Government. Neither the United States Government nor the University of California nor any of their employees, makes any warranty, express or implied, or assumes any legal liability or responsibility for the accuracy, completenest, or usefutness of any information, apparatus, product, or process disclosed. or represents that its use would not infringe privately owned rights. Reference herein to any specific commercial products, process, or service by trade name, trademark, manufactarer, or otherwise. does not necessarily constitute or imply its endorsement. recommendation. or lavoring by the United States Government or the University of California. The views and opinions of authors expressed herein do not necessarily state or reflect those of the United States Government or the University of California, and stall not be used for advertising or product endorsement purposes. 


\section{DISCLAIMER}

Portions of this document may be illegible in electronic image products. Images are produced from the best available original document. 



\section{CAPSULE DIMENSION AND IMPLOSION CALCULATION}

The capsule structure is shown in Fig. 1. The ablator is made of beryllium and its outer radius is $0.234 \mathrm{~cm}$. The ablator encloses the fuel layer of solid DT, which has an outer radius of $0.212 \mathrm{~cm}$. The fuel layer encloses low-density DT gas, which serves for spark-plug formation. Figure 2 shows the radiation temperature profile required for implosion, which is peaked at $260 \mathrm{eV}$.

The capsule implosion is calculated with the radiation hydrodynamic code HYADES. ${ }^{1}$ Figure 3 shows the implosion trajectory. The peak velocity of the fuel layer is about $3 \times 10^{7} \mathrm{~cm} / \mathrm{s}$. Estimates show that the fuel layer should be able to survive Rayleigh-Taylor instability that arises during the acceleration and stagnation phase. The capsule reaches the assembled configuration at $38 \mathrm{~ns}$; the energy absorbed by the capsule at this time is $1 \mathrm{MJ}$, and the yield is $430 \mathrm{MJ}$.

\section{HOHLRAUM CONFIGURATION AND ILLUMINATION SYMMETRY}

The hohlraum for the capsule described is shown in Fig. 4. The converters have radius $r_{c}$, and the radius $r_{0}$ of the converter opening is $0.15 \mathrm{~cm}$. The shine shields in front of the converters block the direct-line-of-sight illumination from the converters. By adjusting the positions of the shine shields, $A_{2}$ (where $A_{n}$ represents for the coefficient of the Legendre polynomial $P_{n}$ ) for the flux asymmetry can be minimized. The $A_{4}$ coefficient can be reduced by using the rings located at about $45^{\circ}$. The initial capsule-tohohlraum surface area ratio is about 0.075 . The hohlraum case is made of lead.

To calculate the illumination symmetry of the capsule, it is necessary to consider the fact that the capsule radius decreases with time (as shown in Fig. 3) and that the inward expansion of the hohlraum wall from exposure to radiation with temperature history in Fig. 2. The wall motion is characterized by the motion of the location at which the Rosseland mean optical depth $\tau$ equals unity. The location of this surface as a function of time, calculated using HYADES, is plotted on Fig. 5 for a thin spherical shield with $0.7-\mathrm{cm}$ initial radius, and with the outer radius fixed in time. This figure shows that the surface moves considerably, so that the decrease in area of this surface caused by the spherical convergence is noticeable. The effective albedo of this spherical shell is higher than that for the planar case as shown in Fig. 6. The effective wall albedo is defined as

$$
\alpha_{\text {eff }}=1-\frac{\dot{\mathrm{E}}}{\mathrm{A}_{0} \sigma \mathrm{T}^{4}}
$$

where $\dot{E}$ is the rate of energy absorbed by the shell, $A_{0}$ is the initial area of the spherical shell, $\sigma$ is the Stefan-Boltzmann constant, and $\mathrm{T}$ is the radiation temperature. The expansion of the $\tau=1$ surface can be slowed down somewhat if the hohlraum is filled with a few milligrams of helium. 
IAEA-CN-60/B-P-13

\title{
Radiation-Driven Targets for Heavy-Ion Fusion
}

\author{
D. D.-M. Ho, J. A. Harte, and M. Tabak
}

Lawrence Livermore National Laboratory

Livermore, CA 94550

\begin{abstract}
The baseline hohlraum configuration for heavy-ion fusion has the radiation converters placed at opposite ends. For a capsule that absorbs about $1 \mathrm{MJ}$ and has an initial radius of $0.234 \mathrm{~cm}$, the minimum initial capsule to hohlraum surface area ratio that can provide an adequate time-dependent symmetry requirement for a capsule implosion is about 0.075 , based on calculations using the view factor code GERTIE. The capsule implosion is calculated using the hydrodynamic code HYADES. The energy coupling efficiency between the hohlraum and the capsule is $21 \%$, the peak hohlraum temperature is $260 \mathrm{eV}$, and the gain of this target system can be as high as 80 . By placing the converters outside the hohlraum, the radii of the converters can be varied according to the beam focusing requirements while the hohlraum dimensions remain unchanged. By bending the radiation converters by $90^{\circ}$, one can obtain a hohlraum configuration that requires the ion beams to come in from only one direction.
\end{abstract}


Based on the above information on the trajectory of the capsule radius, hohlraum wall motion, and the wall albedo, the time-dependent illumination asymmetry seen by the capsule (expressed in terms of $\mathrm{A}_{2} / \mathrm{A}_{0}$ and $\mathrm{A}_{4} / \mathrm{A}_{0}$ ) calculated using GERTIE ${ }^{2}$ at various times between 0 and $38 \mathrm{~ns}$, is plotted in Fig. 7. The asymmetry shown in this figure is tolerable from the capsule implosion point of view. Note that the geometry of the rings can be assumed to be roughly constant in time since they can be made of low-density lead foam with a plastic liner (to minimize the expansion of the foam).

To calculate the energy coupling efficiency $\eta_{\mathrm{e}}$ between the capsule and the hohlraum, we use the respective $\alpha_{\text {eff }}$ for the capsule and the hohlraum (the dashed curve in Fig. 6) and let the capsule radius and the hohlraum wall be fixed at their initial locations. The value for $\eta_{\mathrm{e}}$ obtained from GERTIE is about $21 \%$.

\section{RADIATION CONVERTER SYSTEMATICS}

The radiating and beam-stopping material, contained inside the lead converter casing, is composed of beryllium mixed with a small amount of lead. ${ }^{3}$ The converter radius $r_{c}$ is determined by the focal spot size of the ion beams. ${ }^{4}$ Since the converters are placed outside the hohlraum, the hohlraum dimensions can remain invariant even if $r_{c}$ changes (but $r_{0}$ remains constant). The LASNEX ${ }^{5}$ result for the radiation conversion efficiency $\eta_{c}$ is plotted against $r_{c}$ for various beam ion energies in Fig. 8. (The energy absorbed by the casing is already taken into account.) Knowing $\eta_{c}$ and $\eta_{e}$, the gain of the target system can be obtained; the result is plotted in Fig. 8.

\section{NOVEL TARGET CONFIGURATION}

The hohlraum described above requires bending high-current beams using quadrupole magnets, which can be difficult. The hohlraum with the converters bent by $90^{\circ}$, as shown in Fig. 9, requires the beams to come in from only one direction and hence avoids the requirement of beam bending.

\section{CONCLUSION}

Time-dependent calculations show that the hohlraum can satisfy the illumination symmetry requirements for implosion while the target system can still have high gain. Detailed 2-D LASNEX calculations are in progress.

\section{ACKNOWLEDGMENT}

We thank J. D. Lindl, P. A. Amendt, J. T. Larsen, and G. B. Zimmerman for discussions. This work was performed under the auspices of the U.S. Department of Energy by Lawrence Livermore National Laboratory under contract W-7405-Eng-48. 


\section{REFERENCES}

[1] LARSEN, J. T., and LANE, S. M., J. Quant. Spectrosc. Radiat. Transfer 51 (1994) 179.

[2] KIRKPATRICK, R. C., University of California LANL Report No. LA-UR-861038, 1986; ZIMMERMAN, G. B., Lawrence Livermore National Laboratory, Livermore, CA, personal communication (1993).

[3] HO, D. D.-M., LINDL, J. D., and TABAK, M., Nuclear Fusion, in press.

[4] HO, D. D.-M., and CRANDALL, K. R., Particle Accelerators 41 (1993) 153.

[5] ZIMMERMAN, G. B., and KRUER, W. L., Comm. Plasma Phys. Controlled Fusion 2 (1975) 51.

\section{FIGURE CAPTIONS}

Fig. 1. Capsule structure.

Fig. 2. Radiation temperature profile.

Fig. 3. Capsule implosion trajectory.

Fig. 4. Hohlraum configuration.

Fig. 5. Location for the $\tau=1$ surface for the thin spherical lead shell with initial radius of $0.7 \mathrm{~cm}$.

Fig. 6. Albedo of lead for the spherical shell (dashed curve) and for the planar case (solid curve).

Fig. 7. Time dependent illumination asymmetry seen by the capsule expressed in terms of the coefficients of the Legendre polynomial.

Fig. 8. Conversion efficiency $\eta_{c}$ (solid curves) and gain (dashed curves) versus converter radius $r_{c}$ for ion beams with ion kinetic energy of $5,7.5$, and $10 \mathrm{GeV}$.

Fig. 9. Hohlraum configuration that requires the ion beams to come in from only one direction. 


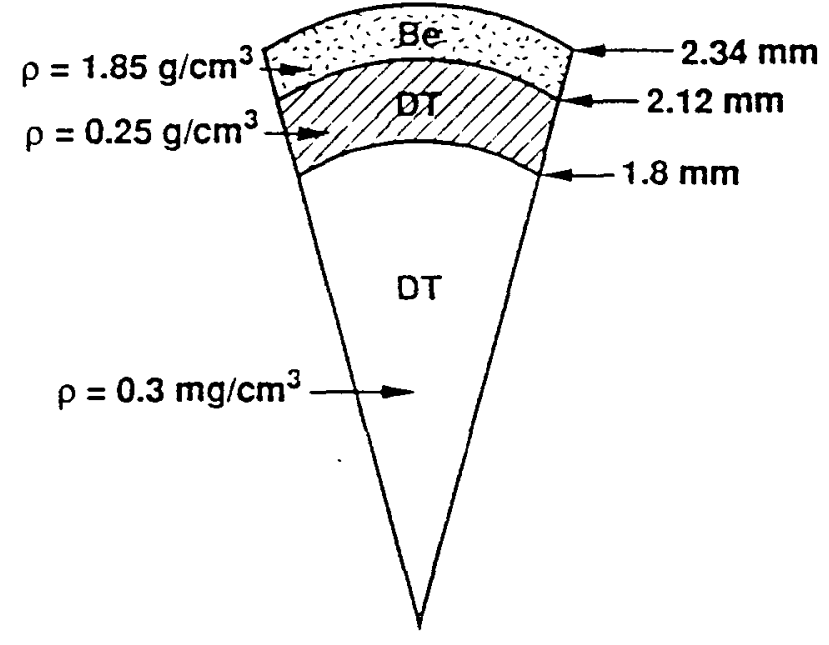

50-01-0894-31650601

160 MHunth

Figure 1 


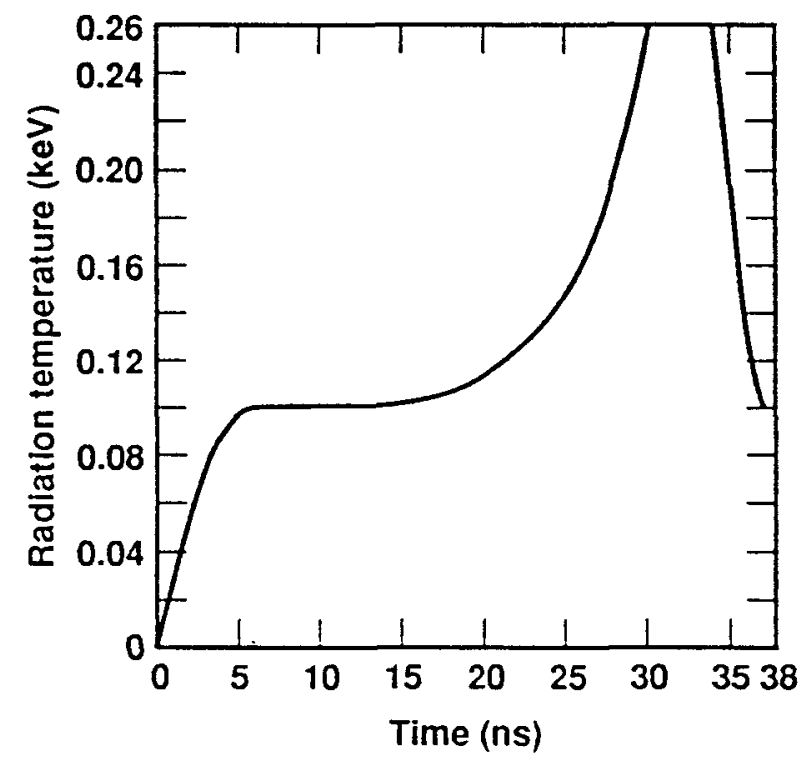

50-01-0894-3164pb01

16DMH//wh

Figure 2 


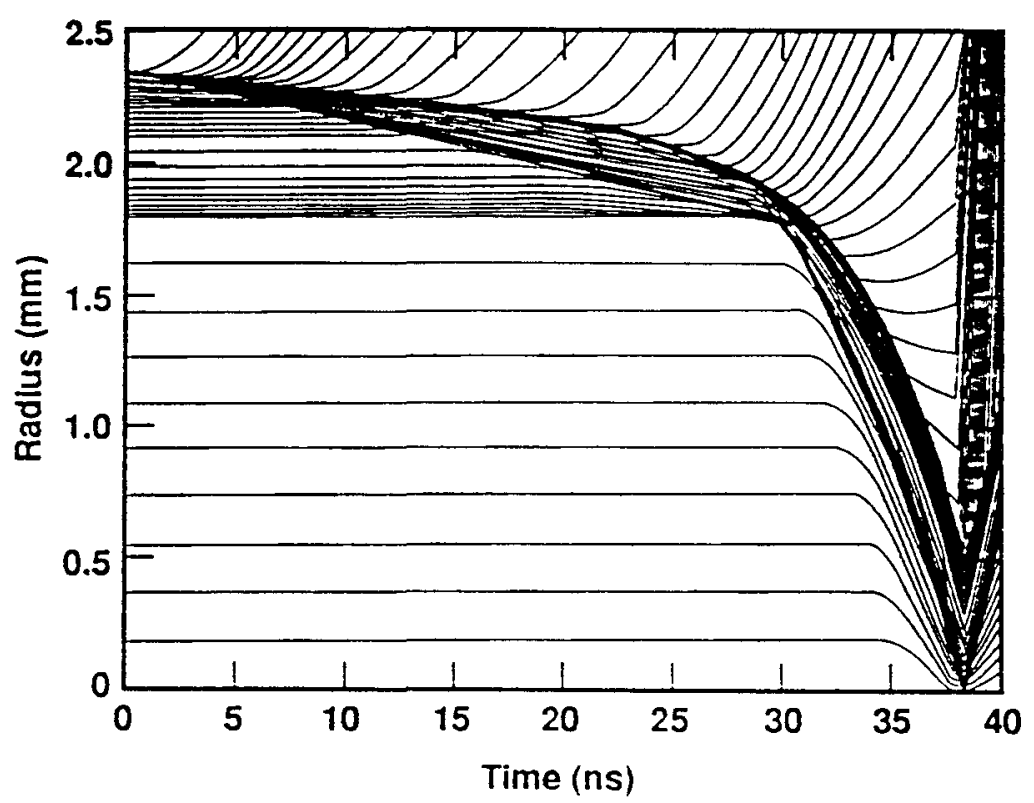

$50-01-0894-31630001$

160 MHMuth

Figure 3 


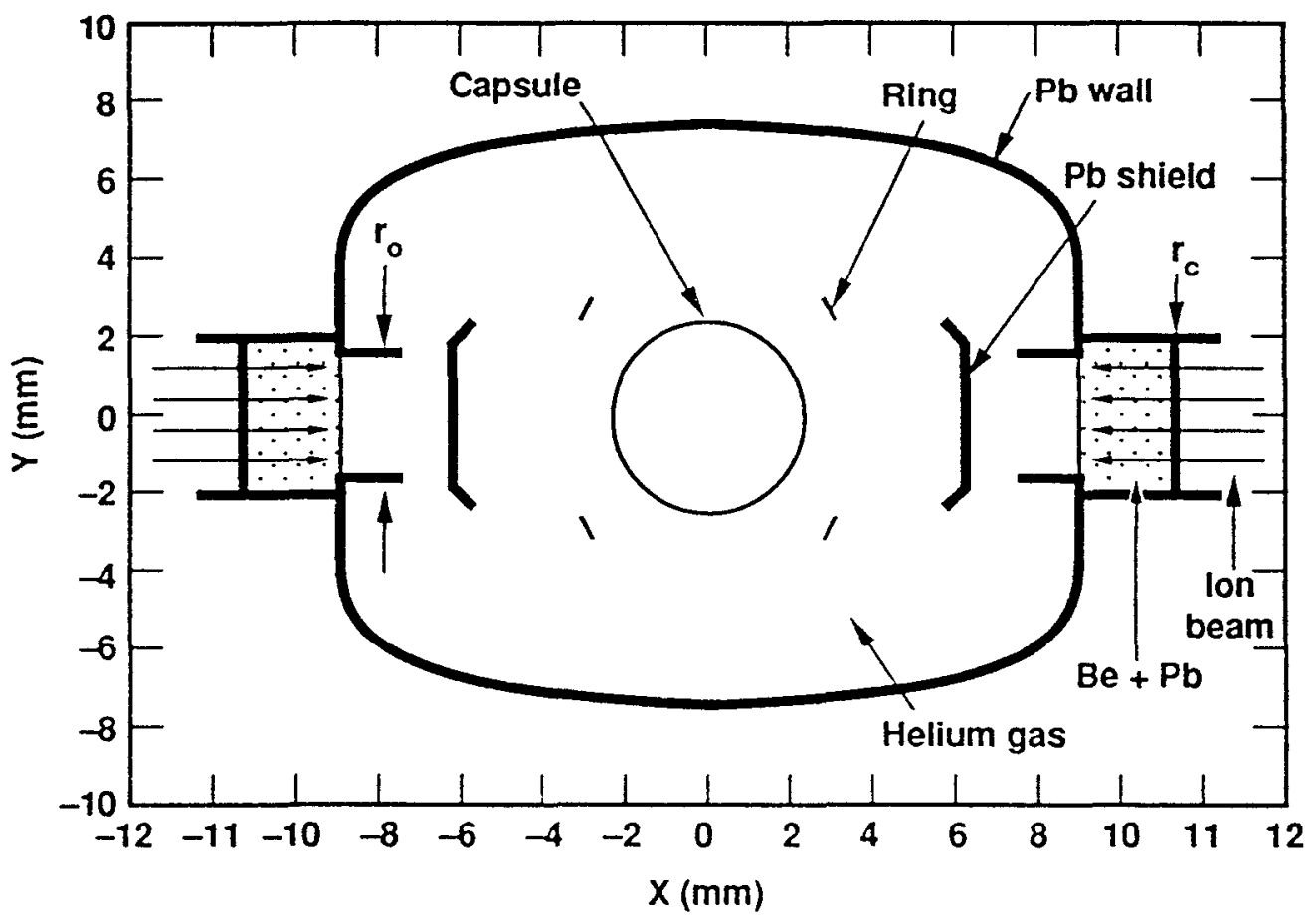

50-01-0894-3177pb02

18DMt-lwh

Figure 4 


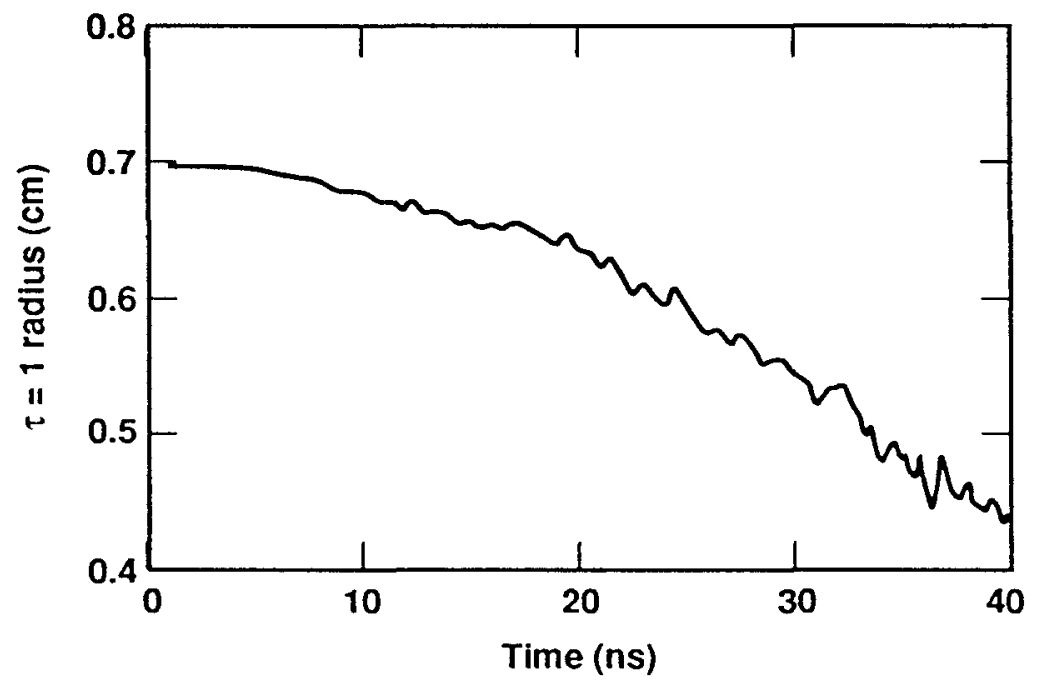

50-01-0894-3168pb01

16DMH/wh

Figure 5 


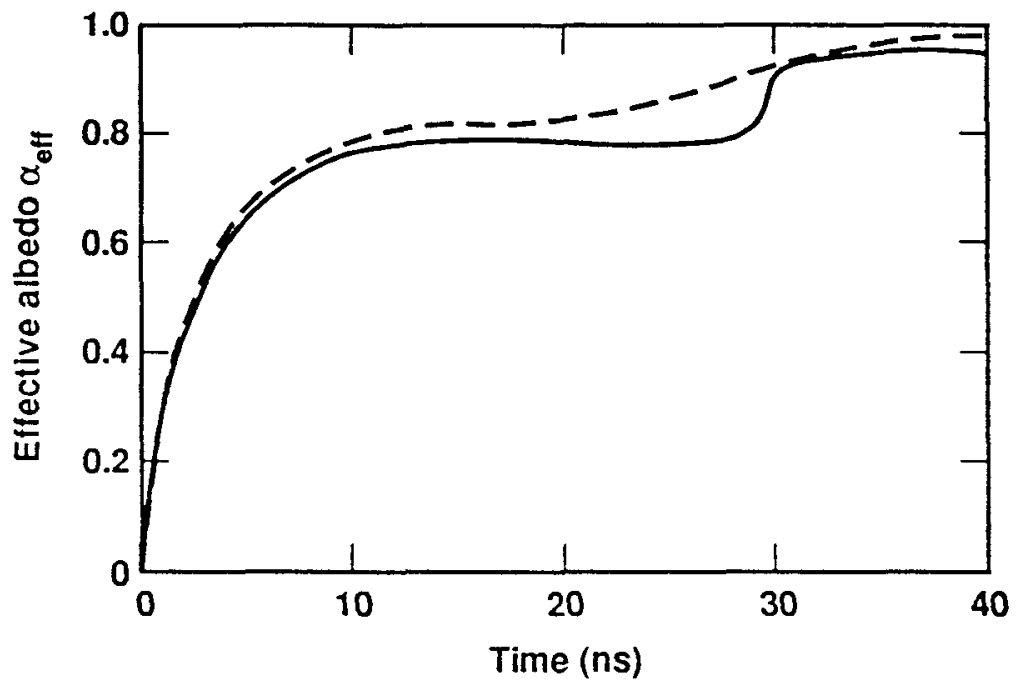

50 01-0894-3167p60

16DMH/wh

Figure 6 


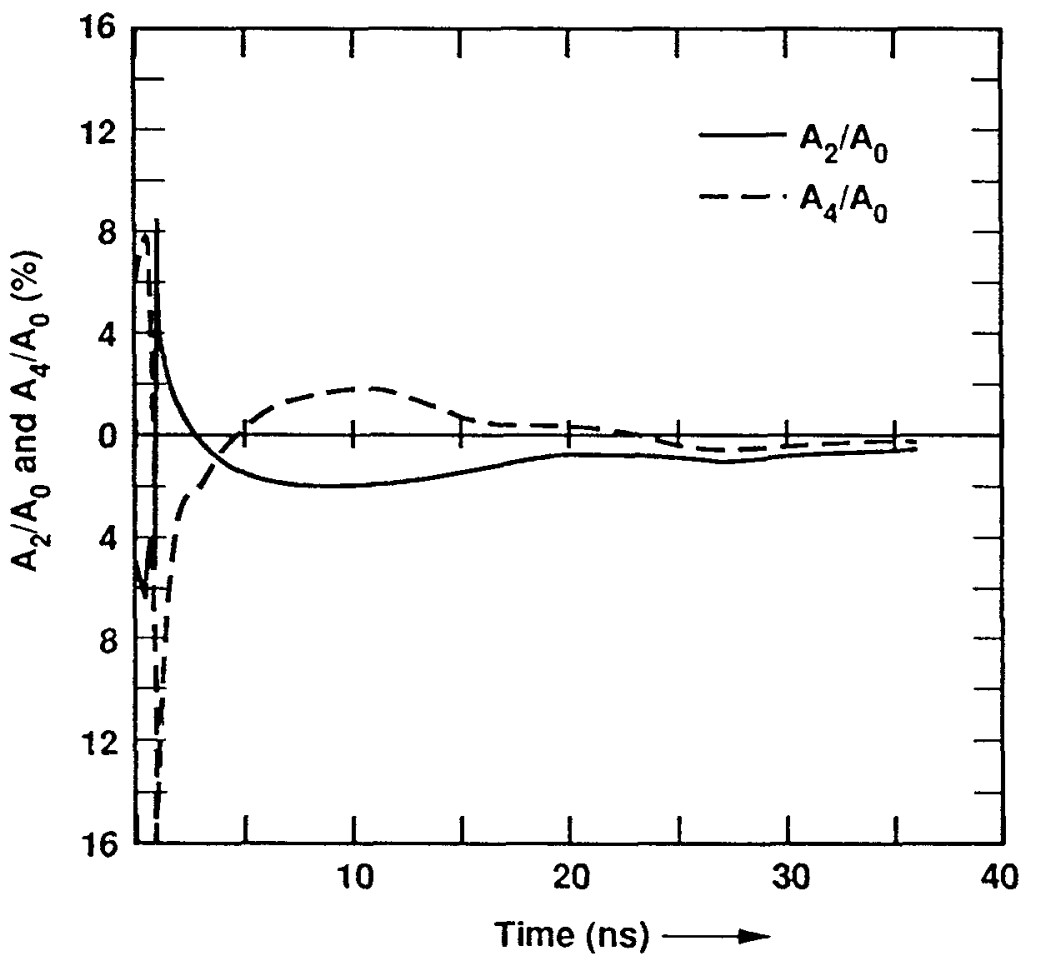

50-01-0894-319200001

$190 \mathrm{MH} / \mathrm{wh}$

Figure 7 


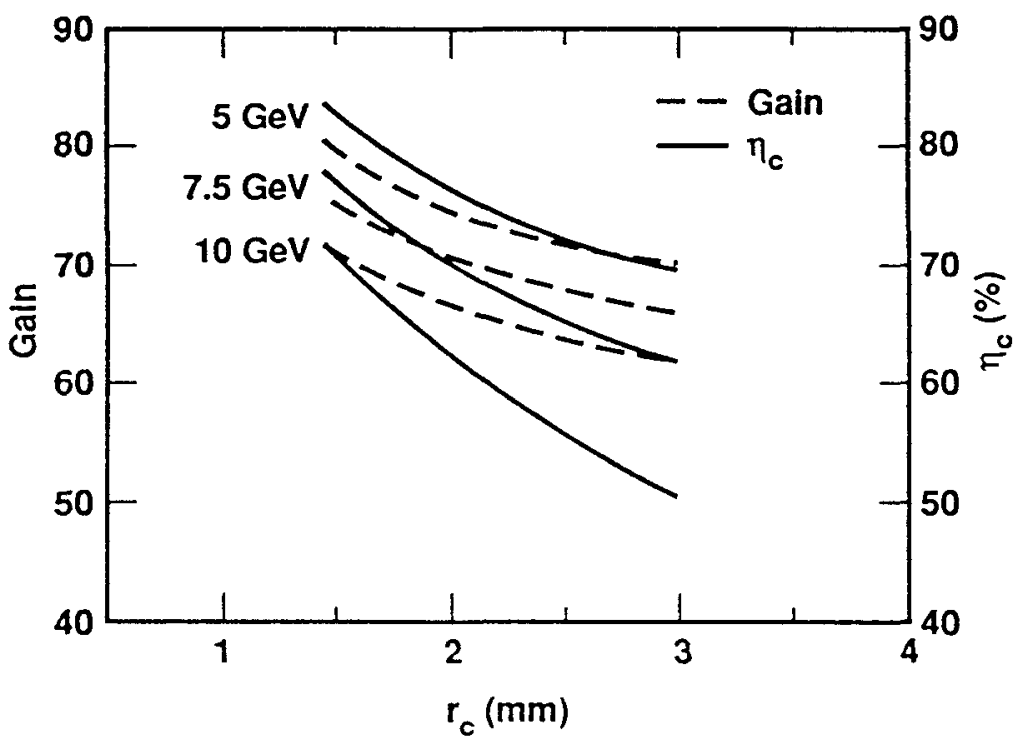

50-01-0894-3176pb01

18DMH/lwh

Figure 8 


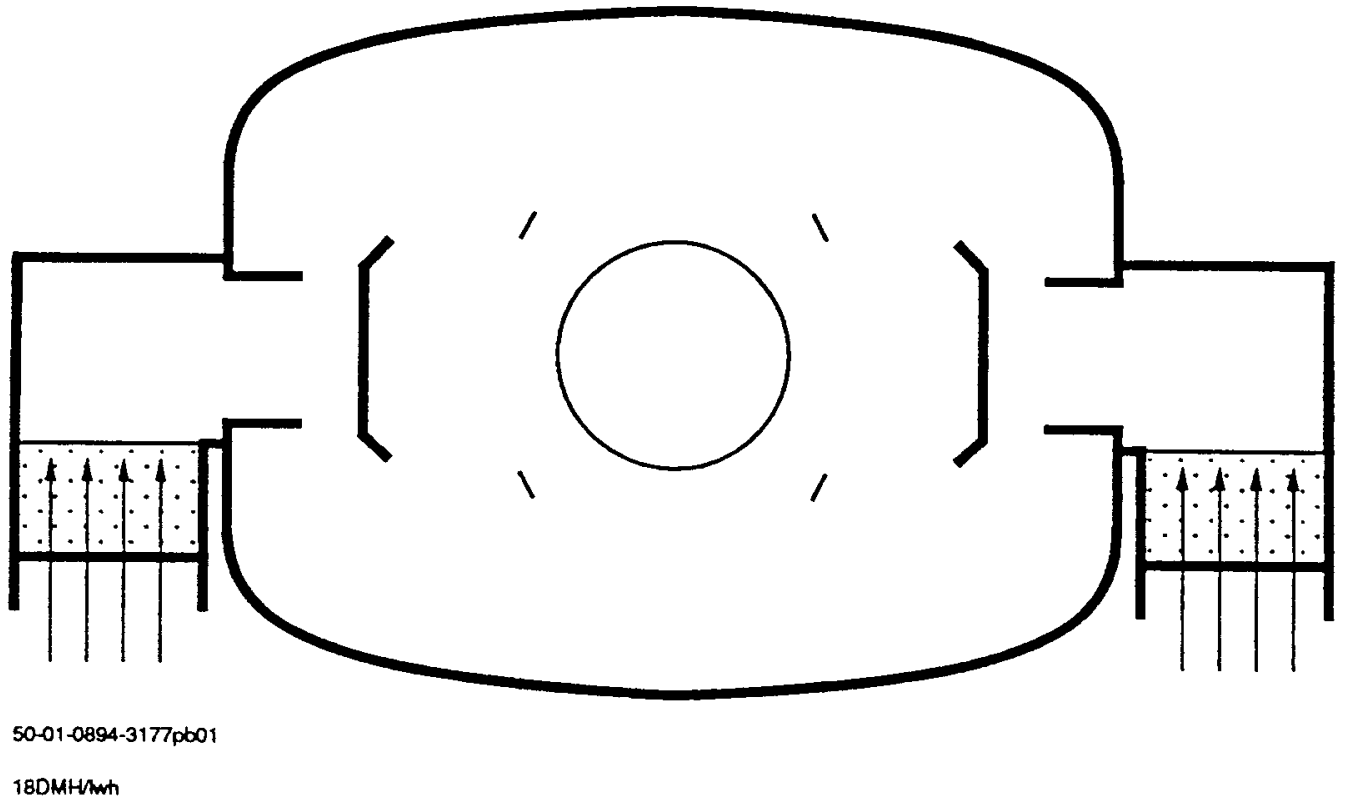

Figure 9 
